\title{
Managing Patients With Vascular Disease and Depression
}

his ACADEMIC HIGHLIGHTS section of

The Journal of Clinical Psychiatry presents the highlights of the series of planning teleconferences "Managing Patients With Vascular Disease and Depression," which were held from June through August 2006. This report was prepared by the CME Institute of Physicians Postgraduate Press, Inc., and was supported by an educational grant from Forest Laboratories, Inc.

The teleconferences were chaired by

Steven P. Roose, M.D., Department of Biological Psychiatry and Clinical Psychopharmacology, Columbia University, New York, N.Y. The faculty were Alexander Glassman, M.D., Division of Psychobiology, Columbia University, New York, N.Y.; Sanjay J. Mathew, M.D., Department of Psychiatry, Mount Sinai School of Medicine, New York, N.Y.; Dominique Musselman, M.D., Department of Psychiatry, Emory University School of Medicine, Atlanta, Ga.; J. Craig Nelson, M.D., Department of Psychiatry, University of California, San Francisco; and David C. Steffens, M.D., Department of Psychiatry and Medicine, Duke University Medical Center, Durham, N.C.

Faculty disclosure: In the spirit of full disclosure and in compliance with all ACCME

Essential Areas and Policies, the faculty for this CME article were asked to complete a statement regarding all relevant financial relationships between themselves or their spouse/partner and any commercial interest (i.e., a proprietary entity producing health care goods or services) occurring within the 12 months prior to joining this activity. The CME Institute has resolved any conflicts of interest that were identified. The disclosures are as follows: Dr. Roose has received grant/research support from Forest and Bristol-Myers Squibb, and is a consultant to Forest, Novartis, Wyeth, Sanofi-Aventis, and Cyberonics. Dr. Glassman is a consultant for. has received grant/research support from, and is on the speakers or advisory board for Pfizer; has received honoraria from Pfizer, Forest. GlaxoSmithKline, and Johnson \& Johnson; and is an expert witness. Dr. Mathew is on the speakers or advisory boards for Pfizer. Cephalon, and AstraZeneca. Dr. Musselman has received research support from GlaxoSmithKline, the National Institutes of Health, Schering-Plough, the DANA Foundation, Pharmacia \& Upjohn, and Janssen; and is on the speakers bureau for GlaxoSmithKline, Forest, Pfizer, and Organon. Dr. Nelson has received research support from Eli Lilly; has received honoraria from Abbott, AstraZeneca, Bristol-Myers Squibb, Eli Lilly, Forest, GlaxoSmithKline, Janssen, Pfizer, and Wyeth; and is on the speakers or advisory boards for Abbott, Biovail, Bristol-Myers Squibb, Corcept, Eli Lilly, GlaxoSmithKline, Orexigen, Organon, Pfizer, Sepracor, and Shire. Dr. Steffens has received honoraria from and is on the speakers or advisory boards for Forest.

The opinions expressed herein are those of the faculty and do not necessarily reflect the views of the CME provider and publisher or the commercial supporter.

\section{Overview}

Opening remarks by Steven $P$. Roose, M.D., set the tone for the serious topic of comorbid vascular disease and depression. In combination, these illnesses are deadly. Depression is a widely prevalent illness. The World Health Organization ${ }^{1}$ predicts that by the year 2020, depression will be the leading cause of morbidity worldwide. In the United States, vascular diseasespecifically cardiac and cerebrovascular disease-is the leading cause of mortality in both women and men. ${ }^{2}$

A complex, multidimensional relationship exists between depression and vascular disease. Depression is a risk factor for the development of both cardiac and cerebrovascular disease, and among patients with manifest vascular disease-either post-myocardial infarction (MI) or poststroke-patients with depression have a substantial increase in mortality compared with comparably ill patients who are not depressed. The question is, Can we interrupt this cycle of depression leading to vascular disease, vascular disease leading to depression, and, ultimately, the increased risk of death caused by comorbidity? Dr. Roose introduced each of the topics that will address this task.

Dominique Musselman, M.D., reviewed the physiologic mechanisms that underlie depression as a risk factor for vascular disease, specifically, the syndrome of hypothalamic-pituitary axis (HPA) hyperactivity in depressed patients and the effect of cortisol on vasculature and on glucose transport. Evidence suggests that stress is associated with increased insulin resistance, perhaps via increased catecholamine activity, which can contribute to vascular damage. Finally, she reviewed the rapidly developing material on the relationship between inflammatory processes, sickness behavior, and noncompliance, and how these come together as a mechanism that may underlie the connection between depression and vascular disease.

The growing body of knowledge on the relationship between diabetes and depression is explored by Sanjay J. Mathew, M.D. First, depression itself is a risk factor for the development of diabetes, and the presence of depression makes glucose control more problematic. Diabetes is not simply a peripheral disease involving insulin resistance, but much of the pathophysiology of diabetes is in the central nervous system.

Alexander Glassman, M.D., reviewed data from treatment studies of post-MI patients with depression. Data from these studies strongly suggest that treatment with selective serotonin reuptake inhibitors (SSRIs) can reduce cardiac mortality, although the mechanism by which this happens is not clear. Data from the Sertraline Antidepressant Heart Attack Randomized Trial (SADHART) $)^{3}$ showed that in approximately $50 \%$ of the patients, depression actually preceded the MI instead of in reaction to it. The physiology of depression may actually have been a critical trigger in the development of the ischemic event.

David C. Steffens, M.D., approached the cycle of depression, vascular disease, and mortality from another direction. The vascular hypothesis of late-onset depression states that vascular disease can cause depression. One view of late-onset depression is that cerebrovascular changes produce 
ischemia in certain critical areas that, in vulnerable patients (patients made vulnerable by genetic diathesis, psychosocial stressors, or other events), results in a depressive illness. Others consider late-onset vascular depression a variant of poststroke depression, but that remains to be demonstrated. If it is true that depression is a variant of poststroke depression, then the cycle is complete in that depression early in life may lead to cerebrovascular disease, and then the ischemic changes wrought by the cerebrovascular disease cause depression.

Finally, J. Craig Nelson, M.D., discussed the prevalence, diagnosis, and principles of treatment in depression in the medically ill. Depression is both common and persistent in the medically ill, although often difficult to diagnose because patients present with physical symptoms that obscure the psychosocial complaints. Clinicians should evaluate patient mood and recommend treatment for those who would benefit from pharmacotherapy. Concerns regarding drug-drug interaction, response and remission rates, adherence, and strategies to improve adherence are important aspects of treating the medically ill with comorbid depression.

Dr. Roose concluded by explaining that preventing vascular disease and/or diabetes by treating vascular risk factors and depression in patients with ischemic disease is a key way to disrupt this cycle.

\section{The Relationship Between Depression and Vascular Disease}

Dominique L. Musselman, M.D., examined the epidemiologic evidence regarding depression as a risk factor for heart disease and stroke, the pathophysiologic connections that underlie major depression and thrombovascular disease, and how psychiatric treatment might prevent or delay the development of thrombovascular disease.

\section{Epidemiology of Depression and Risk for Heart Disease and Stroke}

In the United States, heart disease is the leading cause of mortality, responsible for over one quarter of deaths each year. ${ }^{2}$ Diabetes, a disease that contributes to heart disease and stroke, is the sixth leading cause of death. ${ }^{4}$ Cross-sectional studies have shown prevalence rates from $5 \%$ to $10 \%$ for depression among medical outpatients and $10 \%$ to $14 \%$ for medical inpatients with different medical illnesses. The prevalence rate of depression is even greater among those patients with diabetes, and ranges from $9 \%$ to $27 \%,{ }^{5} 17$ to $23 \%$ among those who have had a heart attack, ${ }^{6}$ and $22 \%$ to $50 \%$ among stroke patients. $^{7}$

During the past 15 years, a series of prospective, community-based, epidemiologic studies have provided further evidence of a strong association between depression, heart disease, and even stroke. For example, the Systolic Hypertension in the Elderly Program $(\text { SHEP) })^{8}$ followed 4367 generally healthy men and women aged 60 years and older for 4.5 years. Participants received placebo or low-dose hypertensive medication and were administered questionnaires including the Center for Epidemiological Studies Depression Scale (CES-D). Approximately $40 \%$ of study subjects experienced a 5-point increase in their depression scores on the CES-D, which was associated with a $25 \%$ increased risk of death (relative risk $[R R]=1.25$; $95 \% \mathrm{CI}=1.15$ to 1.36 ), even after statistically accounting for traditional risk factors for heart disease and stroke. A similar increase of risk for either stroke or MI was shown $(\mathrm{RR}=1.18 ; 95 \%$ $\mathrm{CI}=1.08$ to 1.30 ), and, after statistically controlling for risk of MI, an increase in depressive symptoms was associated with a significant increase of risk of stroke, especially for women $(\mathrm{RR}=1.29 ; 95 \% \mathrm{CI}=1.07$ to 1.34$)$. This study demonstrated that increases in depression raised the risk of vascular disease, be it stroke or MI, and death. A more recent meta-analysis ${ }^{9}$ of 10 of these large-scale, community-based, prospective studies confirmed that the presence of depression significantly increased the risk of development of coronary artery disease $(\mathrm{RR}=1.64$; $95 \% \mathrm{CI}=1.41$ to 1.90 ), after controlling for other atherosclerotic coronary artery disease risk factors. These epidemiologic studies indicate that depression, much like hypertension, smok- ing, or lack of exercise, is an independent risk factor for the development of coronary artery disease.

Depression also decreases survival in individuals who have clinically evident vascular disease. Frasure-Smith and colleagues' seminal study at the Montreal Heart Institute ${ }^{10}$ showed that patients who were depressed had a 3 -fold to 4 -fold increase in risk of death from cardiac causes in the first 6 months after an index myocardial infarction. Recent meta-analysis by other investigators ${ }^{11}$ found similar results; patients were more than 2.5 times more likely to die after a heart attack if they had depression compared with patients who did not have depression (odds ratio $[\mathrm{OR}]$ fixed $=2.59 ; 95 \% \mathrm{CI}=1.77$ to $3.77 ; \mathrm{p}<.00001$ ). Of note is that Lesperance et al. ${ }^{72}$ have studied ${ }^{12} 896$ post-MI patients for 5 years after initial hospitalization. The greater the depressive symptom severity at the time of initial hospitalization, the greater the risk of cardiac-related death during the next 5 years. This large, clinical study shows a stepwise, dose-response correlation between greater depressive symptom severity and diminished survival.

Dr. Musselman remarked that a growing number of studies indicate that depression also seems to be an independent risk factor for diabetes, even after adjustment for usual risk factors. One such study is a prospec- 
tive, community-based, epidemiologic survey $^{13}$ of 6190 individuals who did not have diabetes at baseline and were followed for 15 years. Those research participants with severe depression exhibited markedly elevated rates of incidence of diabetes ( 7.3 per 1000 person-years) compared with people who had low levels of depression (3.6 per 1000 person-years; $\mathrm{p}<.01$ ).

Dr. Musselman summarized these studies by saying that patients with depression not only exhibit a higher rate of development of heart disease, stroke, and diabetes, but once vascular diseases are manifested, depressed patients suffer diminished quality of life, and premature death.

\section{Pathophysiology of Depression and Thrombovascular Disease}

Dr. Musselman went on to discuss a hypothetical model of the neurobiological linkage between depression and vascular disease. ${ }^{6}$ She proposed that depression in people's early years initiates "direct vascular damage" that in later years causes further stress on the brain and induction of depressive symptoms. Initially, mental stress activates the HPA-cortical axis and the sympathomedullary axis, with resulting increases in cortisol and catecholamines, respectively. Cortisol causes atherosclerosis by inducing hypercholesterolemia, hypertriglyceridemia, and hypertension and by inhibiting normal healing. Catecholamines, in addition to increasing heart rate and stress within blood vessels, stimulate platelets in a manner that increases their stickiness and ability to aggregate.

Furthermore, depression causes patients to become inactive, which, combined with increased cortisol levels, causes insulin resistance, adiposity, and obesity. The adipose tissue and damaged blood vessels then release proinflammatory cytokines that feed back to the brain, causing depressive symptoms, which further inhibit a patient's motivation for health promoting behaviors and impairs mental function. This cycle of events eventually results in the development of type 2 diabetes, or a heart attack or stroke. For a long time, it has been understood that HPA-axis hyperactivity and associated increases in plasma cortisol concentrations decrease glucose transport. Moreover, mental stress-induced sympathomedullary inactivation and release of catecholamines (which "counter-regulate" or counteract insulin action) contribute to insulin resistance. The accumulation of adipose tissue and atherosclerosis in vessel walls results in the release of increased levels of proinflammatory cytokines, soluble polypeptide molecules (such as tumor necrosis factor [TNF]-alpha, interleukin [IL]-1, and IL-61, which mediate the inflammatory response) induce sickness behavior. ${ }^{14}$ Winokur and colleagues ${ }^{15}$ showed that depressed patients who were young, relatively healthy, and without typical risk factors for type 2 diabetes already showed evidence of insulin resistance, likely due to decreased exercise and increased release of stress hormones, which counteract insulin (e.g., cortisol and catecholamines), and proinflammatory cytokines. Dr. Musselman explained that proinflammatory cytokines are potent stimulators of the HPA axis and are increasingly recognized for their potent effects on brain function and profound alteration in behavior. ${ }^{16}$ In fact, sickness behavior is a constellation of nonspecific signs and symptoms that accompany the physiologic response to infection or inflammation, including fatigue, anhedonia, malaise, hypersomnia, anorexia, social withdrawal, and poor concentration. This syndrome contains symptoms that overlap with depressive symptoms. ${ }^{16}$ Greater levels of proinflammatory cytokines have been strongly associated with lower insulin sensitivity. ${ }^{17}$

Dr. Musselman stated that these cytokines stimulate the liver to generate commonly measured inflammatory markers such as C-reactive protein (CRP). Elevated CRP indicates that damage and associated inflammation has occurred somewhere in the body. A large, cross-sectional analysis of
6900 men and women under 40 years of age ${ }^{18}$ was performed to examine the relationship between depression and increased levels of CRP. Care was taken to account for known causes of increased CRP (such as nicotine use and obesity). There was no association between depression and CRP in women; in men, however, CRP was more elevated substantially in those men who had a recent episode of severe depression. These data suggested that in these relatively young men, depression caused inflammation in their vasculature, or some occult source of inflammation resulted in elevations in CRP and an associated depressive episode.

\section{Psychiatric Management of Thrombovascular Disease}

Dr. Musselman then turned to the question of psychiatric treatment that might help prevent and/or delay the development of clinically evident thrombovascular disease. A small number of studies ${ }^{19}$ have examined the effect of antidepressant treatment on platelet activation of depressed patients without, and with, ischemic heart disease (IHD). A study by Pollock et al. ${ }^{19}$ showed that prior to randomized, double-blind treatment with either the selective serotonin reuptake inhibitor (SSRI) paroxetine or the nonspecific tricyclic nortriptyline, patients with IHD and depression exhibited greater plasma concentrations of 2 platelet secretion factors, platelet factor 4 (PF4) and beta thromboglobulin $(\beta-\mathrm{TG})$, indicating that the platelets had become sticky, despite these patients' ingestion of aspirin. After 6 weeks of treatment, markedly decreased levels of both PF4 and $\beta$-TG were observed in those patients treated with the SSRI paroxetine, but not in those who received nortriptyline. Though SSRI inhibition of neuronal reuptake of serotonin has been known for decades, the clinical impact upon vessel health by these agents is now becoming more appreciated. Because SSRIs block platelet serotonin transporters, serotonin levels fall within this important 
cell, with consequent decreases in platelet aggregation means. Thus SSRIs might be conceptualized as a new class of platelet-affecting agents, somewhat like aspirin, especially for depressed patients who have suffered a heart attack or stroke. Counterbalancing this potential SSRI benefit, however, are other multiple studies, one of which is a retrospective cohort study ${ }^{20}$ that revealed a greater risk of gastrointestinal (GI) bleeding in patients aged
80 years and older who had been prescribed SSRIs with great avidity for the serotonin transporter. Thus, in elderly patients who have suffered a heart attack, especially those with a history of GI bleeding, somatic treatment of depression may be more optimal with electroconvulsive therapy or an antidepressant class other than SSRIs.

Dr. Musselman concluded that strong evidence indicates depression is a major, independent risk factor for the development of coronary artery disease, stroke, and diabetes. Furthermore, although depression occurs in many patients who have had a heart attack or stroke, disabling depression should not be an accepted emotional consequence of vascular disease. In fact, for patients with vascular disease, the syndrome of depression can be deadly and should be identified and treated as such.

\section{The Bidirectional Relationship Between Diabetes and Depression}

Sanjay J. Mathew, M.D., began his discussion by outlining the problems associated with the management of comorbid diabetes and depression, two chronic and disabling illnesses. He explained that major depressive disorder (MDD) and related mood disorders in patients with diabetes are associated with poor metabolic control, poor adherence to medications and diet, reduction in quality of life, and an increase in overall health care expenditures. ${ }^{21}$ Similarly, inadequate management of diabetes in patients with mood disorders may exacerbate psychiatric symptoms, contribute to persistent fatigue, and diminish response to treatment, both psychological and somatic.

\section{Prevalence}

Dr. Mathew first reviewed the prevalence of diabetes. A survey from the Centers for Disease Control and Prevention $(\mathrm{CDC})^{22}$ suggested that as many as 20.8 million people, or $7 \%$ of the U.S. population, have diabetes. The CDC data showed age-associated and racial and ethnic differences in the prevalence of diabetes. In patients over 60 , the prevalence of diabetes was greater than 20\%. American Indians had the highest prevalence of diabetes with rates over $18 \%$; rates among nonHispanic blacks were about 15\%, 14\% for Hispanic/Latino Americans, and $8 \%$ for non-Hispanic whites.

When referring to type 2 diabetes, the term adult onset is now regarded as a misnomer as the mean age at onset has decreased. About $8 \%$ to $45 \%$ of all new cases of diabetes in children and adolescents are type $2 .^{23}$

Depression, including MDD, dysthymia, bipolar disorder, and seasonal affective disorder, is 3 to 4 times more prevalent in patients with diabetes than in the general population. ${ }^{24}$ Studies have shown that patients with MDD have a higher subsequent relative risk of developing type 2 diabetes. ${ }^{25-27}$ Similarly, patients with type 1 and type 2 diabetes have a higher relative risk of developing mood disorders. ${ }^{5}$

\section{Brain Mechanisms and Diabetes}

Dr. Mathew went on to describe some of the brain and central nervous system mechanisms with regards to diabetes. Historically, diabetes has been viewed as a pancreatic or endocrine disorder or peripheral disorder, not as a brain disorder. One reason for this view was the notion that a peptide the size of insulin would be too large to cross the blood-brain barrier, and thus glucose regulation in the brain would be insulin-independent. More recent research, however, has found that the brain is not insulin insensitive and that brain insulin activity is necessary for normal glucose homeostasis. ${ }^{14}$

The specific neural and anatomical areas of the brain implicated in diabetes are the hippocampal regions such as the dentate gyrus, which has been found to be critical to neurogenesis and gray matter density, and the hypothalamus. Hypothalamic nuclei have been implicated in diabetes, ${ }^{28}$ so this pathway might result in excess secretion of neurotransmitters, which, in conjunction with long-chain polyunsaturated fatty acid deficiency, may damage neurons in the hypothalamus and insulin receptors in the brain. ${ }^{29}$

\section{The Relationship Between Diabetes and Depression}

According to Dr. Mathew, moderating factors exist in the association between diabetes and depression. Behavioral and lifestyle factors such as sedentary lifestyle and poor adherence to treatment play an important role in the development and maintenance of diabetes. Depressed patients are 3 times more likely to be noncompliant with recommendations regarding medication, exercise, and diet. ${ }^{30} \mathrm{De}$ pression is also consistently associated with diabetes complications ${ }^{31}$ as well as hyperglycemia in patients with type 1 or type 2 diabetes. $^{32}$

The metabolic syndrome is described in Table $1 .{ }^{33}$ An important link between the metabolic syndrome and MDD is the accumulation of increased intra-abdominal visceral fat, which, together with increased prothrombotic factors such as plasminogen activator inhibitor 1 and factor VIII activity, may contribute to the increased cardiovascular mortality observed in MDD patients. In patients with diabetes, the 


\begin{tabular}{|c|c|}
\hline Risk Factor & Defining Measure \\
\hline \multicolumn{2}{|c|}{ Abdominal obesity, waist circumference } \\
\hline Men & $>40$ in \\
\hline Women & $>35$ in \\
\hline Fasting triglycerides & $\geq 150 \mathrm{mg} / \mathrm{dL}$ \\
\hline \multicolumn{2}{|l|}{ HDL cholesterol } \\
\hline Men & $<40 \mathrm{mg} / \mathrm{dL}$ \\
\hline Women & $<50 \mathrm{mg} / \mathrm{dL}$ \\
\hline Blood pressure & $\begin{array}{l}\geq 130 / 85 \mathrm{~mm} \mathrm{Hg} \text { or on antihypertensive } \\
\text { medication }\end{array}$ \\
\hline Fasting glucose & $\begin{array}{l}\geq 110 \mathrm{mg} / \mathrm{dL}^{\mathrm{b}} \text { or on insulin or hypoglycemic } \\
\text { medication }\end{array}$ \\
\hline \multicolumn{2}{|c|}{$\begin{array}{l}\text { aAdapted with permission from the Expert Panel on Detection, Evaluation, and Treatment of High } \\
\text { Blood Cholesterol in Adults }{ }^{33} \text { Three criteria must be present to establish diagnosis. } \\
\text { bThe American Heart Association modified definition uses a fasting glucose cutoff of } 100 \mathrm{mg} / \mathrm{dL} \text {. } \\
\text { Abbreviation: HDL = high density lipoprotein. }\end{array}$} \\
\hline
\end{tabular}

presence of comorbid depression is associated with increased morbidity and mortality.

Recent epidemiologic surveys suggest that adverse experiences may be a risk factor for type 2 diabetes. For example, among 3032 individuals, those reporting childhood maternal, emotional, or physical abuse had higher rates of self-reported diabetes in adulthood. $^{34}$ A separate, larger study ${ }^{35}$ of data from 5877 individuals showed an association between childhood neglect and increased risk of diabetes $(\mathrm{OR}=2.2)$. A fundamental limitation of these studies is the retrospective nature of the self-reported physical or sexual abuse.

\section{Implications for Treatment}

Dr. Mathew explained that patients with comorbid depression and diabetes typically respond well to treatment for depression, but it is less clear how this treatment affects glucose control. In a study ${ }^{36}$ by Lustman and colleagues, 152 patients with type 2 diabetes who had been given open-label sertraline for 16 weeks and recovered from MDD were subsequently randomly assigned to receive either sertraline or placebo for up to 1 year. After 4 weeks of open-label treatment with sertraline, patients' glycosylated hemoglobin decreased, although the long-term data showed no differences in placebo- versus sertraline-treated groups.

Katon and colleagues ${ }^{37}$ examined whether enhancing the quality of depression care would improve both diabetes and depression in 329 patients with both disorders. Patients were randomly assigned to either receive treatment as usual or case management intervention, which provided educational and adherence support. The case management model improved depressive symptoms but did not result in improved glycemic control.

Next, Dr. Mathew discussed different classes of medications appropriate for patients with diabetes and depression. When choosing a medication for depression, it is important to consider which drugs cause hypoglycemia and weight gain. Nonselective hydrazine monoamine oxidase inhibitors ${ }^{38}$ and $(\mathrm{TCAs})^{39}$ have been found to increase risk of hypoglycemia. Antidepressants such as nortriptyline ${ }^{40}$ and mirtazapine $^{41}$ are associated with an increase in blood glucose and weight gain. Selective serotonin reuptake inhibitors
Depression and cardiovascular disease are strongly associated, but how they relate to each other is scientifically difficult to prove. Alexander $\mathrm{H}$. Glassman, M.D., explained that the best scientific evidence of a relationship between depression and cardiovascular disease was a meta-analysis ${ }^{9}$ that included 10 large, well-controlled community samples. All 10 studies in- are not exempt from concern in patients with diabetes. In one study, ${ }^{42}$ fluoxetine was found to increase insulin sensitivity. Atypical antipsychotics, which are sometimes prescribed offlabel for depression, have been found to cause weight gain and increased glucose levels. ${ }^{32,40,43}$

New agents that have not yet gained U.S. Food and Drug Administration (FDA) approval might offer new treatments for patients with diabetes and depression. One example is rimonabant, the first in the class of selected cannabinoid-1 receptor blockers. The endocannabinoid system has been implicated in body mass regulation, insulin resistance, and lipid metabolism. ${ }^{44}$ Rimonabant and other similar endocannabinoid receptor drugs might be useful for treating diabetes and anxiety disorders associated with the metabolic syndrome.

Dr. Mathew stressed that, in this population, medications that are weight-neutral should be recommended as first-line agents. These medications may not improve glycemic control, so behavioral therapies that promote weight reduction with regular exercise and dietary modification are critical to long-term success.

Dr. Mathew emphasized that the health of diabetic patients with depression should be viewed within the context of the larger metabolic and cardiovascular risk profiles of the patient. Regular monitoring is critical for patients with one or more risk factors.

\section{Vascular Disease and Depression: Challenges in Management and Treatment}

dicated that individuals who were depressed at baseline but free of any evidence of medical illness were numerically more likely to develop coronary disease. The overall relative risk indicated that subjects with depression were at 65\% $(\mathrm{RR}=1.64[95 \%$ $\mathrm{CI}=1.41$ to 1.90$]$ ) greater risk for onset of coronary disease than subjects who were not depressed at baseline. 


\section{Figure 1. Cumulative Mortality for Depressed and Nondepressed Patients Following Myocardial Infarction (MI) ${ }^{\mathrm{a}}$}

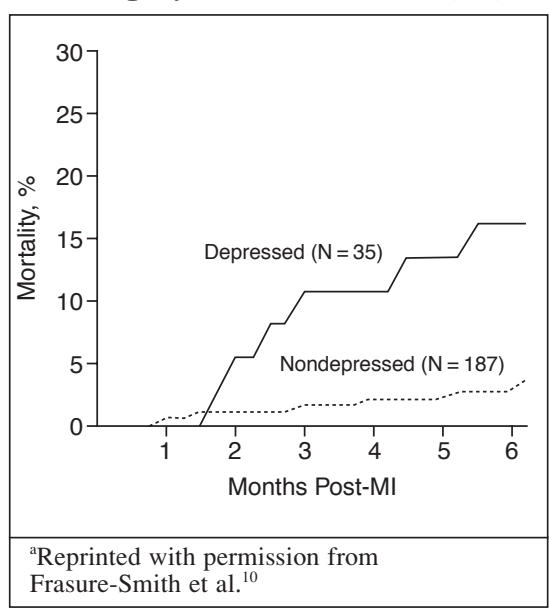

Dr. Glassman remarked that the reason this approach was used was a concern that heart disease was causing depression and that following healthy controls who already had depression, but not heart disease, would eliminate that concern.

\section{Depression and \\ Preexisting Cardiac Disease}

In a landmark 1993 study $^{10}$ of the effect of major depression on patients with preexisting cardiac disease, Frasure-Smith and colleagues examined 222 consecutive MI patients in a cardiac intensive care unit and followed them for 6 months following their heart attack. Figure $1^{10}$ shows the 6-month mortality rate of depressed versus nondepressed patients. Depression was a significant predictor of mortality (adjusted hazard ratio $=4.29$ [95\% $\mathrm{CI}=3.14$ to $5.44 ; \mathrm{p}=.013]$ ).

The increased risk of dying from coronary disease comorbid with major depression was replicated by a Swedish study ${ }^{45}$ that included 275 post-MI patients who were followed for 10 years. High depression scores again increased the risk for coronary mortality by approximately the same 3.5 -fold that had been seen in the original Canadian study. Subsequently, the Canadian group combined a series of their studies looking at the ability of depressive symptoms to predict cardiac-related mortality following MI. On examining Beck Depression Inventory scores among 896 post-MI patients, symptoms of depression were found to be significant predictors of mortality $(\mathrm{p} \leq .001)$ after adjusting for cardiac risk factors and disease severity. ${ }^{46}$ The strong relationship between depressive symptoms and the risk of medical mortality observed in this study prompted the next generation of investigation to address the question, Would treating post-MI depression reduce medical mortality?

\section{Depression and Medical Mortality}

Two investigations ${ }^{3,47}$ of patients hospitalized for acute MI provide data suggesting that SSRIs can reduce medical events and, by extension, reduce mortality.

SADHART. SADHART ${ }^{3}$ was a multicenter study of 369 patients with MDD who were admitted to a hospital for either acute MI or unstable angina. The study was designed to evaluate the safety and efficacy of sertraline treatment in these patients. Patients were randomly assigned to receive sertraline in flexible doses ranging from 50 to $200 \mathrm{mg} /$ day $(\mathrm{N}=186)$ or placebo $(\mathrm{N}=183)$ for 24 weeks. The primary safety outcome measure was change from baseline in left ventricular ejection fraction; at 16 weeks, no difference was found between the active drug and placebo. No differences in heart rate, blood pressure, electrocardiogram measures, or ventricular premature contractions, i.e., extra beats, were seen between sertraline and placebo. Dr. Glassman explained that efficacy of the sertraline was tricky to determine in SADHART because patients were not seeking treatment for depression, their depressive symptoms were generally mild, and the depression was of short duration. Therefore, a high placebo response rate was expected. ${ }^{48}$

A subgroup of patients with recurring major depression ( $\geq 1$ prior episode of MDD) was identified. Since prior history of depression is a strong predictor of chronicity, the question of

\section{Figure 2. Efficacy in Post-Myocardial Infarction Patients Receiving Sertraline or Placebo at Week $24^{\mathrm{a}}$}

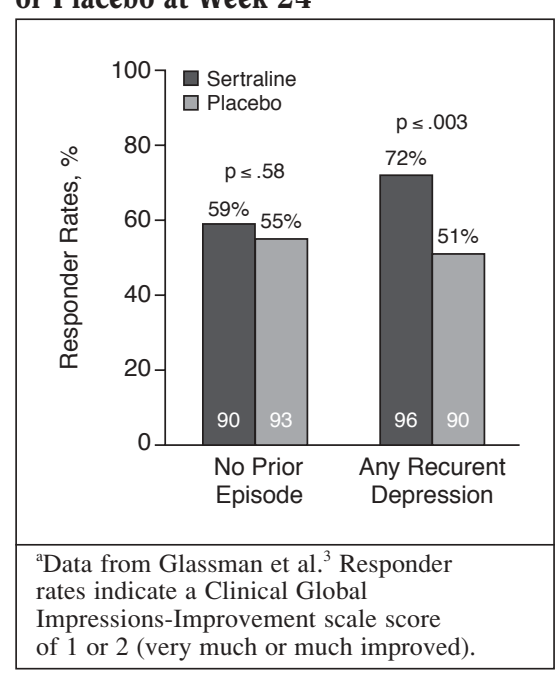

interest became, Would it also be a predictor of drug response? The drug effect for the total sample was weak. However, the response to sertraline in the subgroup of patients who had no prior episode of depression was not significantly different than that of placebo responders (Figure 2). ${ }^{3}$ Conversely, patients with any prior history of depression showed a statistically significant, clinically meaningful difference in response to sertraline.

Dr. Glassman reported that SADHART investigators expected that since a heart attack is a stressful event in both psychological and physiologic terms, many patients would experience a mild and brief reactive type of depression post-MI. Interestingly, more than half (about 53\%) of patients had depression that began prior to hospitalization for acute coronary syndrome, and less than half developed depression after hospitalization. Patients who were already taking an antidepressant at hospital admission were continued on their medication but excluded from this study, which equated to about $20 \%$ additional patients with MDD.

This realization that patients with coronary disease were depressed prior to their heart attack led to another question. Does antidepressant response differ between patients treated before a coronary event compared with those 
whose episode began in the hospital and who had no prior history of depression? A dramatic, robust drug effect in the patients whose episode began before hospitalization and who had a prior history of MDD was observed. ${ }^{3}$ Dr. Glassman pointed out that a prior history of depression and initiation of treatment before a coronary event are not criteria that a clinician would typically use to make the decision about treating depression after a heart attack. In fact, most clinicians would make this treatment decision on the basis of the severity of the depression. These observations suggest that prior depression history, onset prior to hospitalization, and severity (scores $\geq 20$ on the Hamilton Rating Scale for Depression [HAM-D]) were independent predictors of clinical response. Each predicted about a 35\% increase in response compared with placebo. ${ }^{3}$ The more characteristics a patient had, the better the drug response compared with placebo.

One of the most striking observations was the lack of life-threatening events in people who had been treated with sertraline. A composite ${ }^{49}$ of the risk for death, recurrent MI, stroke, hospitalization for angina, and hospitalization for congestive heart failure showed that patients who had received sertraline were $23 \%$ less likely to have one of these life-threatening events than those who received placebo. SADHART was not powered to examine medical outcomes, and not surprisingly the observed reduction was not statistically significant. However, further evidence came from another multicenter study, the Enhanced Recovery in Coronary Heart Disease (ENRICHD) trial. ${ }^{47}$

ENRICHD. ENRICHD enrolled 2481 post-MI patients. The objective of this clinical study was to test whether treating depression and perceived low social support with cognitive behavioral therapy (CBT) and SSRIs soon after the coronary event would reduce mortality and recurrent MI. Patients were randomly assigned to CBT or treatment as usual. Although patients who received CBT experienced reduced depression and feelings of increased social support, especially during the first 6 months, the interven- tion did not reduce mortality. Post hoc secondary analyses ${ }^{50}$ of the ENRICHD data during a mean follow-up of 29 months reported that risk of death or recurrent MI was significantly lower in patients taking SSRIs (adjusted hazard ratio $=0.57$ [95\% $\mathrm{CI}=0.38$ to 0.84$]$ ).

The ENRICHD study has severe limitations. It was neither randomized nor controlled; only the most depressed patients, those known to be at higher risk for cardiac events, were offered antidepressants in this study; and drug initiation and discontinuation were not recorded systematically. Nonetheless, the sample was large and the magnitude of the effect represents a $42 \%$ decrease in life-threatening outcomes.

\section{Conclusion}

Taken together, these 2 studies, although not definitive, strongly suggest that SSRI treatment can reduce medical events as well as depression in postMI patients. Dr. Glassman pointed out that even without evidence of reduced mortality, MDD is an illness of the whole body and that post-MI depression is a treatable illness.

\section{Poststroke Depression and the Vascular Depression Hypothesis}

David C. Steffens, M.D., began his presentation by outlining the prevalence and duration of poststroke depression. About 700,000 new and recurrent cases of stroke are reported each year in the United States, and about 5.5 million Americans currently live with the consequences of a stroke, which is a major cause of chronic disability. ${ }^{51,52}$

\section{Predictors, Course, and Consequences of Stroke and Depression}

Dr. Steffens explained that predictors of poststroke depression include severity of the stroke, physical disability after the stroke, and presence of cognitive impairment with the stroke. ${ }^{53,54}$ Social factors that predict poststroke depression include whether patients live alone, the extent of their social support, and the extent of their social isolation. ${ }^{55}$

Little is known about the course of depression after a stroke, but it appears to vary widely among individuals. Astrom and colleagues ${ }^{55}$ found that depression peaked several months after a stroke and then declined to about $50 \%$ of initial rates at 1 year after a stroke. Robinson and colleagues ${ }^{56}$ reported the natural course of poststroke depression to be spontaneous remission about 1 to 2 years after a stroke; 1 year after the stroke, nearly $68 \%$ of individuals had no depression, $14 \%$ had MDD, and $18 \%$ had dysthymia. Rates were similar 24 months after the stroke. ${ }^{56}$

The course of depression may depend on the timing of the onset of depression after a stroke. Depression occurring within a few days after a stroke is more likely to be associated with spontaneous remission than is onset of depression 7 weeks or later after a stroke. ${ }^{57}$ The presence of depression after a stroke increases disability in patients compared with poststroke patients who did not have depression. ${ }^{55}$ Poststroke depression also affects rehabilitation outcomes adversely. ${ }^{58}$ Depression impairs recovery ${ }^{59}$ and contributes to an increased rate of mortality. ${ }^{60}$

\section{Causes of Poststroke Depression}

Poststroke depression is thought to originate either from a structural mechanism, in which ischemic insults directly affect neural circuits involved in mood regulation, or from social and psychological stressors associated with 


\begin{tabular}{|c|c|}
\hline Structural Mechanisms & Psychosocial Mechanisms \\
\hline $\begin{array}{l}\text { Depression more common after stroke than } \\
\text { in other physical illnesses with similar } \\
\text { levels of physical disability }{ }^{61} \\
\text { Left-sided lesions (especially in anterior and } \\
\text { basal ganglia) associated with depression }{ }^{62} \\
\text { Association between lesion location and } \\
\text { poststroke depression stronger in early } \\
\text { poststroke period }^{63}\end{array}$ & $\begin{array}{l}\text { Structural studies have not been replicated } \\
\text { A meta-analysis }{ }^{64} \text { found no relationship } \\
\text { between lesion location and depression } \\
\text { Social isolation is an important risk factor } \\
1 \text { year after stroke, but not immediately } \\
\text { after the stroke } \\
\text { Disability and major life events lead to } \\
\text { depression } \\
\text { Similarity found between poststroke } \\
\text { depression and other late-life } \\
\text { depressions }^{66}\end{array}$ \\
\hline
\end{tabular}

the stroke. Dr. Steffens presented evidence that both structural mechanisms and psychosocial mechanisms may be the cause of poststroke depression (Table 2). ${ }^{61-66}$ The evidence that poststroke depression is related to structural mechanisms supports the idea that specific changes to important neural circuits may lead to depression that accompanies stroke. However, many of the structural studies used as evidence for this hypothesis have not been replicated.

Dr. Steffens commented that poststroke depression is a good model for a biopsychosocial illness because both biological and psychosocial factors are likely to influence its development. Disruption of circuits involved in normal maintenance of mood may increase vulnerability to depression, and poor social support and coping skills in the face of overwhelming life stressors may increase vulnerability to depression. $^{53}$

\section{Treatment of Poststroke Depression}

In a Cochrane database review, ${ }^{67}$ no strong evidence was found that either pharmacotherapy or psychotherapy is of benefit to patients in attaining complete remission of poststroke depression. Some evidence of improvement in scores on depression rating scales was reported, along with an increase in the proportion of participants with anxiety at the end of the follow-up period. Dr. Steffens advised caution in interpreting these results because many studies only required a significant reduction in depressive symptoms, not a complete remission of depression.
Dr. Steffens pointed out that although some studies show no advantage for treating patients for poststroke depression, a study by Robinson and colleagues $^{68}$ of poststroke depression found an improvement of mood symptoms for nortriptyline compared with either placebo or fluoxetine. Furthermore, Fruehwald et al. ${ }^{69}$ noted no substantial difference in response for fluoxetine versus placebo in an initial 12-week trial, but in an 18-month continuation, a difference in depression symptoms between fluoxetine and placebo was found, suggesting delayed beneficial effects of antidepressants in the treatment of poststroke depression. This study has yet to be replicated.

Dr. Steffens noted that antidepressants can be helpful in the acute treatment of poststroke depression. However, positive effects of antidepressant medication may not become apparent until after an acute rehabilitation period. Evidence ${ }^{70}$ favors some SSRIs and TCAs, although the latter have the potential to cause side effects and adverse events relative to the cardiovascular system and must be used judiciously.

\section{Vascular Depression and Comorbid Cerebrovascular Disease and Depression}

Dr. Steffens reported that the term vascular depression is used to describe a subtype of late-onset depression originally defined as depression in the presence of vascular risk factors, accompanying neuropsychological deficits, and distinct brain pathology seen on structural imaging. Patients with comorbid cerebrovascular disease and depression or vascular depression are at increased risk of being treatment refractory to medication monotherapy. ${ }^{71}$ They are also at risk for cognitive decline and the development of dementia, ${ }^{72}$ worsening functional impairment, ${ }^{73}$ and increased mortality. ${ }^{74}$

A review by Dr. Steffens and colleagues ${ }^{75}$ found that patients with geriatric depression, particularly those with late-onset depression, had more vascular changes than nondepressed control subjects. Subcortical white matter lesions in both the deep white matter and periventricular areas and subcortical gray matter lesions, particularly in the basal ganglia, were more common in depressed patients according to computed tomography and magnetic resonance imaging.

Most researchers have examined vascular depression in the context of a working hypothesis in which ischemic vascular lesions cause a disruption in key circuits, or a disconnection syndrome. The areas of particular concern include the prefrontal cortex and striatum. One consequence of these changes is executive dyscontrol. In the dorsolateral prefrontal cortex, classic frontal impairments such as difficulty in multitasking, sequencing, and decision-making occur. Changes in the ventromedial prefrontal cortex may result in impairment in cognitive control over the emotional response.

According to Dr. Steffens, in the area of vascular depression, there are several unanswered questions. First is the question whether poststroke depression is a form of vascular depression or whether poststroke depression and vascular depression may be seen as different constructs. Vascular depression implies an accumulation of "silent" vascular lesions in depressed older adults, whereas poststroke depression may be seen as a focal insult leading to depression. Second, Dr. Steffens questioned whether subcortical vascular changes accompany or result from acute stroke syndrome. Many patients with a discrete stroke episode are found to have a moderate 
to severe amount of accompanying cerebrovascular disease. Third, he questioned whether subcortical cerebrovascular changes contribute to the development of depression among stroke patients. The effects of stroke versus the effects of smaller subcortical changes are difficult to disentangle but may be important in understanding whether someone will develop depression and what his or her course of depression will be. Fourth, he asked whether a large, strategically placed ischemic stroke lesion can have depressive consequences similar to an accumulation of smaller ischemic vascular lesions. Finally, the question remains whether depression brings about vascular change.

Dr. Steffens concluded that poststroke depression can be considered to be a vascular depression if a con- sequence of acute stroke is disruption of circuits involved in maintaining a normal mood state. Neurological and mood changes may be the outcome of complex, interrelating factors, both disruption of circuits and the experience of psychosocial depression. Lateral thinking may be necessary to understand the relationship between vascular disease, stroke, and depression.

\section{Diagnosis and Treatment of Depression in Patients With Medical Illness}

To emphasize the importance of proper diagnosis and treatment of depression among medically ill patients, J. Craig Nelson, M.D., reviewed the prevalence of affective disorders in the general population. According to data from the National Comorbidity Survey, ${ }^{76}$ the lifetime prevalence of major depression is about $17 \%$, which indicates that 1 person in 6 will experience depression during his or her lifetime. In addition, depression has been found to be more prevalent in persons with chronic medical conditions, particularly cancer, heart disease, neurological disorder, and physical handicap. ${ }^{77}$

Dr. Nelson commented that clinicians tend to think of depression as a very common disorder among older, community-dwelling patients, when in fact, the prevalence of major depression increases with medical illness, not age. $^{76,78,79}$ Older patients in medical clinics and residential settings tend to have an elevated prevalence of depression, but they also tend to have comorbid medical illnesses. Depression is also more persistent in medically ill patients perhaps because it presents an ongoing, chronic stress from which patients may be unable to recover. ${ }^{79}$

\section{Diagnosis of Depression}

According to Dr. Nelson, diagnosing depression in a primary care setting is one of the greatest challenges facing clinicians because many depressed patients present with physical symptoms. In an international study ${ }^{80}$ of 1146 patients with major depression, $69 \%$ reported only physical symptoms as the reason for visiting their clinician. In another study, ${ }^{81}$ of 75 patients diagnosed with major depression or anxiety disorder, $76 \%$ of patients initiated their office visit with complaints of somatic symptoms. Kirmayer and colleagues ${ }^{81}$ found that somatization reduced physician recognition of depression or anxiety. They found that the likelihood that a patient with a depression or anxiety disorder would be correctly diagnosed was only $22 \%$ for those presenting with somatic symptoms compared with $77 \%$ for those who presented with psychosocial complaints. Some somatic symptoms of depression such as fatigue or lack of appetite can occur with medical disorders. Symptoms that are more specific for depression include loss of interest, loss of pleasure, hopelessness, worthlessness, guilt, and suicidal ideation. $^{82}$

\section{Treatment of Depression}

Untreated depression is associated with a variety of adverse effects_-poor quality of life, diminished sense of well-being, impaired functioning, and increased risk of suicide. Depression can also increase mortality and result in poor outcome of medical illness. For these reasons, treatment of medically ill depressed patients is especially important.

Dr. Nelson stated that it is important to recognize that depression in medically ill patients does respond to treatment. Response and remission rates, however, may decline as the severity of medical comorbidity increases. Dr. Nelson referred to an open-label study ${ }^{83}$ of 384 outpatients who met DSM-III-R criteria for MDD. Patients were treated with fluoxetine, $20 \mathrm{mg} /$ day, for 8 weeks and were rated using the Cumulative Illness Rating Scale (CIRS) to measure the burden of medical comorbidity as well as the 17-item HAM-D to assess changes in depressive symptoms. Patients with scores greater than 4 on the CIRS were much less likely to respond or remit than patients with less severe illness (Figure 3). ${ }^{83}$ The 28-week continuation phase $^{84}$ of this study found that patients with greater medical comorbidity were indeed more likely to experience relapse.

Dr. Nelson added that medically ill patients, who are often older, may also be more vulnerable to adverse drug reaction. Medically ill depressed patients are more likely to be receiving other medications and, therefore, may be at risk for drug interactions.

Dr. Nelson stated that clinically important drug interactions require not only that the interactive drug acts on a specific pathway, but that the magnitude of the effect is substantial. Antidepressants that have clinically meaningful inhibition of the cytochrome P450 (CYP450) enzymes include fluvoxamine, paroxetine, fluoxetine, bupropion, and duloxetine. Those that 
Figure 3. Severity of Medical Comorbidity as Measured by Scores on the Cumulative Illness Rating Scale (CIRS) Predicts Antidepressant Response and Remission ${ }^{\mathrm{a}}$

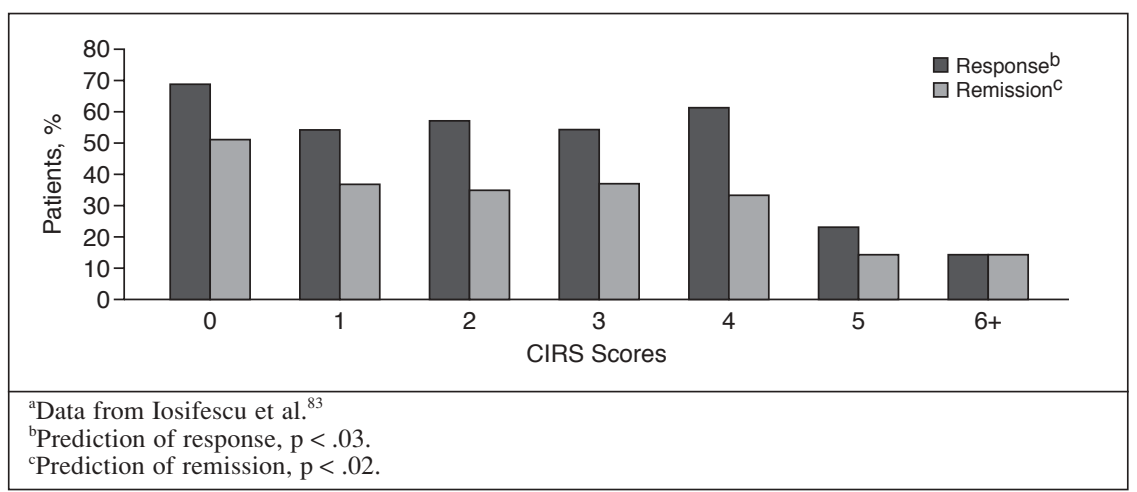

Figure 4. Comparison of Response and Remission Rates in 3 "Real-World" Studies

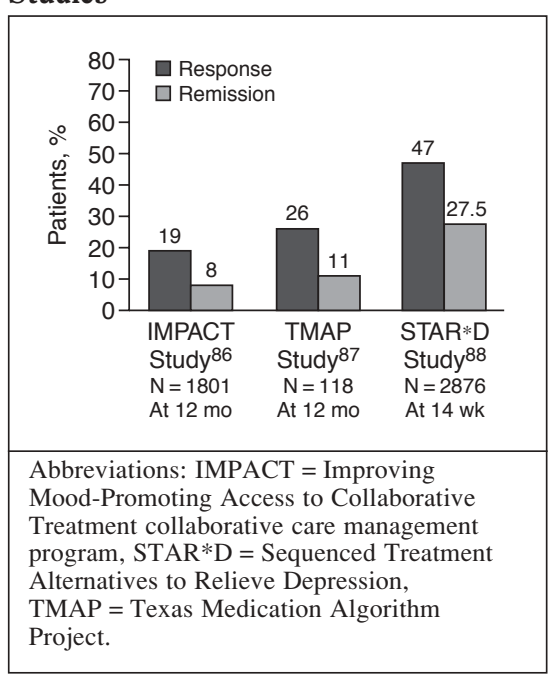

have a relatively modest effect on CYP450 enzymes include venlafaxine, mirtazapine, sertraline, citalopram, and escitalopram. ${ }^{85}$

\section{Effectiveness of Treatment}

Dr. Nelson presented data from 3 large studies ${ }^{86-88}$ of the effectiveness of antidepressants in clinical practice settings: the Improving Mood-Promoting Access to Collaborative Treatment (IMPACT) collaborative care management program, ${ }^{86}$ the Texas Medication Algorithm Project (TMAP), ${ }^{87}$ and the Sequenced Treatment Alternatives to Relieve Depression (STAR*D) study. ${ }^{88}$ Response and remission rates at 14 weeks for the STAR*D study and at 12 months for the TMAP study and the "treatment as usual" group in the IMPACT study are shown in Figure $4{ }^{86-88}$ Dr. Nelson commented that low response and remission rates may be a reflection of "real world" patients who may be more likely to have comorbid psychiatric and medical conditions than patients in clinical trials. In addition, the IMPACT study found that $39 \%$ of the patients in the "treatment as usual" group never received an adequate course of either antidepressant treatment or psychotherapy compared with $18 \%$ in the IMPACT intervention group. ${ }^{86}$ This suggests that some patients may feel stigmatized by the diagnosis of depression and may be reluctant to receive treatment. The IMPACT study demonstrated that education, case management, and careful monitoring of side effects increased the number of patients who received and accepted adequate treatment.

Education and attentive care, coupled with appropriate psychosocial interventions, are also important elements of rehabilitation programs for medically ill patients. Dr. Nelson cited a study ${ }^{89}$ of patients with coronary artery disease who were examined before and after completion of a cardiac rehabilitation and exercise training program. Results showed reductions in cardiac risk factors, anxiety, depression, and somatization and improvements in physical function and adherence. Similarly, diabetes education programs have helped to improve management and adherence..$^{90,91}$ A meta- analysis $^{92}$ of 23 controlled studies that evaluated the impact of psychosocial treatment in coronary artery disease found that psychosocial interventions combined with rehabilitation programs resulted in reduced mortality and morbidity.

\section{Conclusion}

To summarize, Dr. Nelson restated that major depression is a common disorder that is even more common in patients who are medically ill. Depression increases the risk of some medical adverse events, such as MI, and adversely affects the course of the medical illness. Fortunately, depression responds to treatment, but a coordinated approach that not only includes the use of an antidepressant but also includes education, medical rehabilitation, and sometimes psychotherapy in addition to sufficient follow-up will help patients adhere to treatment and maintain the benefits of early treatment effects.

Drug names: bupropion (Wellbutrin and others), citalopram (Celexa and others), duloxetine (Cymbalta), escitalopram (Lexapro), fluoxetine (Prozac and others), mirtazapine (Remeron), nortriptyline (Pamelor, Aventyl, and others), paroxetine (Paxil, Pexeva, and others), sertraline (Zoloft and others), venlafaxine (Effexor and others).

Disclosure of off-label usage: The chair has determined that, to the best of his knowledge, no investigational information about pharmaceutical agents that is outside U.S. Food and Drug Administration-approved labeling has been presented in this activity.

\section{ReFERENCES}

1. Murray CJL, Lopez AD, eds. The Global Burden of Disease: A Comprehensive Assessment of Mortality and Disability From Diseases, Injuries, and Risk Factors in 1990 and Projected to 2020. Cambridge, Mass: Harvard University Press; 1996

2. US Dept of Health and Human Services. Centers for Disease Control and Prevention. Available at: http://www.cdc.gov/ nchs/data/hus/hus.05.pdf\#executive summary. Accessed Aug 22, 2006

3. Glassman AH, O'Connor CM, Califf RM, et al. Sertraline treatment of major depression in patients with acute MI or unstable angina. JAMA 2002;288:701-709

4. Hoyert DL, Kung HC, Smith BL. Deaths: preliminary data for 2003. Natl Vital Stat Rep 2005;53:1-48

5. Anderson RJ, Freedland KE, Clouse RE, et al. The prevalence of comorbid depression in adults with diabetes: a meta-analysis. Diabetes Care 2001;24:1069-1078 
6. Musselman DL, Evans DL, Nemeroff CB The relationship of depression to cardiovascular disease: epidemiology, biology, and treatment. Arch Gen Psychiatry 1998:55:580-592

7. Cohen-Cole SA, Brown FW, McDaniel JS. Diagnostic assessment of depression in the medically ill. In: Stoudemire A, Fogel B, eds. Principles of Medical Psychiatry. Second Edition ed. New York, NY: Oxford University Press; 1993:53-70

8. Wassertheil-Smoller S, Applegate WB, Berge W, et al, for the SHEP Cooperative Research Group (Systolic Hypertension in the Elderly Program). Change in depression as a precursor of cardiovascular events. Arch Intern Med 1996;156: 553-561

9. Wulsin LR, Singal BM. Do depressive symptoms increase the risk for the onset of coronary disease? a systematic quantitative review. Psychosom Med 2003;65:201-210

10. Frasure-Smith N, Lesperance R, Talajic M. Depression following myocardial infarction: impact on 6-months survival. JAMA 1993;270:1819-1825

11. van Melle JP, de Jonge P, Spijkerman TA, et al. Prognostic association of depression following myocardial infarction with mortality and cardiovascular events: a metaanalysis. Psychosom Med 2004;66: 814-822

12. Lesperance F, Frasure-Smith N, Talajic M, et al. Five-year risk of cardiac mortality in relation to initial severity and one-year changes in depression symptoms after myocardial infarction. Circulation 2002;105:1049-1053

13. Carnethon MR, Kinder LS, Fair JM, et al. Symptoms of depression as a risk factor for incident diabetes: findings from the $\mathrm{Na}$ tional Health and Nutrition Examination Epidemiologic Follow-up Study, 1971_ 1992. Am J Epidemiol 2003;158:416-423

14. Musselman DL, Betan E, Larsen H, et al. Relationship of depression to diabetes types 1 and 2: epidemiology, biology, and treatment. Biol Psychiatry 2003;54: 317-329

15. Winokur A, Maislin G, Phillips JL, et al. Insulin resistance after oral glucose tolerance testing in patients with major depression. Am J Psychiatry 1988:145:325-330

16. Musselman DL, Miller AH, Porter MR, et al. Higher than normal plasma interleukin6 concentrations in cancer patients with depression: preliminary findings. Am J Psychiatry 2001;158:1252-1257

17. Fernandez-Real JM, Vayreda M, Richart C, et al. Circulating interleukin 6 levels, blood pressure, and insulin sensitivity in apparently healthy men and women. J Clin Endocrinol Metab 2001;86:1154-1159

18. Ford DE, Erlinger DP. Depression and C-reactive protein in US adults: data from the Third National Health and Nutrition Examination Survey. Arch Intern Med 2004;164:1010-1014

19. Pollock BG, Laghrissi-Thode F, Wagner WR. Evaluation of platelet activation in depressed patients with ischemic heart disease after paroxetine or nortriptyline treatment. J Clin Psychopharmacol 2000;20:137-140

20. van Walraven C, Mamdani MM, Wells PS, et al. Inhibition of serotonin reuptake by antidepressants and upper gastrointestinal bleeding in elderly patients: retrospective cohort study. BMJ 2001;323:655-658

21. Lustman PJ, Clouse RE. Depression in diabetic patients: the relationship between mood and glycemic control. J Diabetes Complications 2005;19:113-122

22. National Diabetes Information Clearinghouse (NDIC). National Diabetes Statistics. NIH Publication No 06-3892. November 2005. Available at http:// diabetes.niddk.nih.gov/dm/pubs/statistics/ index.htm\#7. Accessed July 28, 2006

23. Kaufman FR. Type 2 diabetes mellitus in children and youth: a new epidemic. J Pediatr Endocrinol Metab 2002;15 (suppl 2):737-744

24. Brown ES, Varghese FP, McEwan BS. Association of depression with medical illness: does cortisol play a role? Biol Psychiatry 2004;55:1-9

25. Eaton WW, Armenian H, Gallo J, et al. Depression and risk for onset of type II diabetes: a prospective population-based study. Diabetes Care 1996;19:1097-1102

26. Kawakami N, Takatsuka N, Shimizu H, et al. Depressive symptoms and occurrence of type 2 diabetes among Japanese men. Diabetes Care 1999;22:1071-1076

27. Everson-Rose SA, Meyer PM, Powell LH, et al. Depressive symptoms, insulin resistance, and risk of diabetes in women at midlife. Diabetes Care 2004;27:2856-2862

28. Boden G, Hoeldtke RD. Nerves, fat, and insulin resistance. N Engl J Med 2003;349: 1966-1967

29. Klein JP, Waxman SG. The brain in diabetes: molecular changes in neurons and their implications for end-organ damage. Lancet Neurol 2003;2:548-554

30. DiMatteo MR, Lepper HS, Croghan TW. Depression is a risk factor for noncompliance with medical treatment: meta-analysis of the effects of anxiety and depression on patient adherence. Arch Intern Med 2000; 160:2101-2107

31. de Groot M, Anderson R, Freedland KE, et al. Association of depression and diabetes complications: a meta-analysis. Psychosom Med 2001;63:619-630

32. Lustman PJ, Anderson RJ, Freedland KE et al. Depression and poor glycemic control: a meta-analytic review of the literature. Diabetes Care 2000;23:934-942

33. Expert Panel on Detection, Evaluation, and Treatment of High Blood Cholesterol in Adults. Executive summary of the third report of the National Cholesterol Education Program (NCEP) Expert Panel on Detection, Evaluation, and Treatment of High Blood Cholesterol in Adults (Adult Treatment Panel III). JAMA 2001;285. 2486-2497

34. Goodwin RD, Weisberg SP. Childhood abuse and diabetes in the community [letter]. Diabetes Care 2002;24:801-802

35. Goodwin RD, Stein MB. Association between childhood trauma and physical disorders among adults in the United States. Psychol Med 2004;34:509-520

36. Lustman PJ, Clouse RE, Nix BD, et al. Sertraline for prevention of depression recurrence in diabetes mellitus: a randomized, double-blind, placebo-controlled trial. Arch Gen Psychiatry 2006;63:521-529

37. Katon WJ, Von Korff M, Lin EH, et al. The Pathways Study: a randomized trial of collaborative care in patients with diabetes and depression. Arch Gen Psychiatry 2004;61:1042-1049

38. McIntyre RS, Soczynska J, Konarski JZ, et al. The effect of antidepressants on glucose homeostasis and insulin sensitivity: synthesis and mechanisms. Expert Opin Drug Saf 2006;5:157-168

39. Goodnick PJ, Henry JH, Buki VM. Treatment of depression in patients with diabetes mellitus. J Clin Psychiatry 1995;56: $128-136$

40. Lustman PJ, Griffith LS, Clouse RE, et al. Effects of nortriptyline on depression and glycemic control in diabetes: results of a double-blind, placebo-controlled trial. Psychosom Med 1997;59:241-240

41. Fisfalen ME, Hsiung RC. Glucose dysregulation and mirtazapine-induced weight gain [letter]. Am J Psychiatry 2003;160:797

42. Maheux P, Ducros F, Bourque J, et al. Fluoxetine improves insulin sensitivity in obese patients with non-insulin-dependent diabetes mellitus independently of weight loss. Int J Obes Relat Metab Disord 1997; 21:97-102

43. McEvoy JP, Meyer JM, Goff DC, et al. Prevalence of the metabolic syndrome in patients with schizophrenia: baseline results from the Clinical Antipsychotic Trials of Intervention Effectiveness (CATIE) schizophrenia trial and comparison with national estimates from NHANES III. Schizophr Res 2005;80:19-32

44. Despres JP, Golay A, Sjostrom L, et al. Effects of rimonabant on metabolic risk factors in overweight patients with dyslipidemia. N Engl J Med 2005; 353:2121-2134

45. Welin C, Lappas G, Wilhelmsen L. Independent importance of psychosocial factors for prognosis after myocardial infarction. J Intern Med 2000;247:629-639

46. Frasure-Smith N, Lesperance F. Depression and other psychological risks following myocardial infarction. Arch Gen Psychiatry 2003;60:627-636

47. Berkman LF, Blumenthal J, Burg M, et al. Effects of treating depression and low perceived social support on clinical events after myocardial infarction: the Enhancing Recovery in Coronary Heart Disease Patients (ENRICHD) Randomized Trial. JAMA 2003;289:3106-3116

48. Posternak MA, Zimmerman M, Keitner GI, et al. A reevaluation of the exclusion criteria used in antidepressant efficacy trials. Am J Psychiatry 2002;159:191-200

49. O'Connor CM, Glassman AH, Harrison DJ. Pharmacoeconomic analysis of sertraline treatment of depression in patients with unstable angina or a recent myocardial infarction. J Clin Psychiatry 2005;66: 346-352

50. Taylor CB, Youngblood ME, Catellier D, et al. Effects of antidepressant medication on morbidity and mortality in depressed patients after myocardial infarction. Arch Gen Psychiatry 2005;62:792-798

51. American Heart Association Statistics Committee and Stroke Statistics Subcommittee. Heart disease and stroke statistics: 2006 update. Circulation 2006;113: e85-e151. Available at http:// www.circ.ahajournals.org/cgi/content/full/ 113/6/e85. Accessed Aug 16, 2006

52. Burvill PW, Johnson GA, Jamrozik KD, et al. Prevalence of depression after stroke: 
the Perth Community Stroke Study. Br J Psychiatry 1995; 166:320-327

53. Whyte EM, Mulsant BH. Post stroke depression: epidemiology, pathophysiology, and biological treatment. Biol Psychiatry 2002;52:253-264

54. Hackett ML, Anderson CS. Predictors of depression after stroke: a systematic review of observational studies. Stroke 2005;36: 2296-2301

55. Astrom M, Adolfsson R, Asplund K. Major depression in stroke patients: a 3-year longitudinal study. Stroke 1993;24:976-982

56. Robinson RG, Bolduc PL, Price TR. Two-year longitudinal study of poststroke mood disorders: diagnosis and outcome at one and two years. Stroke 1987; 18: 837-843

57. Andersen G, Vestergaard K, Lauritzen L. Effective treatment of poststroke depression with the selective serotonin reuptake inhibitor citalopram. Stroke 1994;25: 1099-1104

58. Gillen R, Tennen H, McKee TE, et al. Depressive symptoms and history of depression predict rehabilitation efficiency in stroke patients. Arch Phys Med Rehabil 2001;82:1645-1649

59. Parikh RM, Robinson RG, Lipsey JR, et al The impact of poststroke depression on recovery in activities of daily living over a 2-year follow-up. Arch Neurol 1990;47: 785-789

60. House A, Knapp P, Bamford J, et al. Mortality at 12 and 24 months after stroke may be associated with depressive symptoms at 1 month. Stroke 2001;32:696-701

61. Folstein MR, Maiberger R, McHugh PR. Mood disorder as a specific complication of stroke. J Neurol Neurosurg Psychiatry 1977;40:1018-1020

62. Robinson RG, Szetela B. Mood change following left hemispheric brain injury. Ann Neurol 1981;9:447-453

63. Robinson RG, Kubos KL, Starr LB, et al. Mood disorders in stroke patients: importance of location of lesion. Brain 1984;107, pt 1:81-93

64. Carson AJ, MacHale S, Allen K, et al. Depression after stroke and lesion location: a systematic review. Lancet 2000;356: $122-126$

65. Herrmann M, Wallesch CW. Depressive changes in stroke patients. Disabil Rehabil 1993; 15:55-66

66. House A. Depression associated with stroke. J Neuropsychiatry Clin Neurosci 1996;8:453-457

67. Hackett ML, Anderson CS, House AO. Interventions for treating depression after stroke. Cochrane Database Syst Rev 2004:CD003437

68. Robinson RG, Schultz SK, Castillo C, et al. Nortriptyline versus fluoxetine in the treatment of depression and in short-term recovery after stroke: a placebo-controlled, double-blind study. Am J Psychiatry 2000; 157:351-359

69. Fruehwald S, Gatterbauer E, Rehak P, et al. Early fluoxetine treatment of post-stroke depression: a three-month double-blind placebo-controlled study with an openlabel long-term follow up. J Neurol 2003;250:347-351

70. Rampello L, Battaglia G, Raffaele R, et al. Is it safe to use antidepressants after a stroke? Expert Opin Drug Saf 2005;4: 885-897

71. Simpson S, Baldwin RC, Jackson A, et al. Is subcortical disease associated with a poor response to antidepressants? neurological, neuropsychological and neuroradiological findings in late-life depression. Psychol Med 1998;28: 1015-1026

72. Steffens DC, MacFall JR, Payne ME, et al. Grey-matter lesions and dementia [letter]. Lancet 2000:19:1686-1687

73. Steffens DC, Bosworth HB, Provenzale JM, et al. Subcortical white matter lesions and functional impairment in geriatric depression. Depress Anxiety 2002;15:23-28

74. Levy RM, Steffens DC, McQuoid DR, et al. MRI lesion severity and mortality in geriatric depression. Am J Geriatr Psychiatry 2003;11:678-682

75. Steffens DC, Krishnan KR. Structural neuroimaging and mood disorders: recent findings, implications for classification, and future directions. Biol Psychiatry 1998:43:705-712

76. Kessler RC, McGonagle KA, Zhao S, et al. Lifetime and 12-month prevalence of DSM-III-R psychiatric disorders in the United States. Arch Gen Psychiatry 1994:51:8-19

77. Wells KB, Golding JM, Burnam MA. Psychiatric disorder in a sample of the general population with and without chronic medical conditions. Am J Psychiatry 1988;145: 976-981

78. Mulsant BH, Ganguli M. Epidemiology and diagnosis of depression in late life. J Clin Psychiatry 1999;60(suppl 20):9-15

79. Koike AK, Unützer J, Wells KB. Improving the care for depression in patients with comorbid medical disease. Am J Psychiatry 2002;159:1738-1745

80. Simon GE, Von Korff M, Piccinelli M, et al. An international study of the relation between somatic symptoms and depression. N Engl J Med 1999;341:1329-1335

81. Kirmayer LJ, Robbins JM, Dworkind M. Somatization and the recognition of depression and anxiety in primary care. Am J Psychiatry 1993;150:734-741

82. Clark DC, von Ammon CS, Gibbons RD, The core symptoms of depression in medical and psychiatric patients. J Nerv Ment Dis 1983;171:705-713

83. Iosifescu DV, Nierenberg AA, Alpert JE, et al. The impact of medical comorbidity on acute treatment in major depressive disorder. Am J Psychiatry 2003;160: 2122-2127

84. Iosifescu DV, Nierenberg AA, Alpert JE, et al. Comorbid medical illness and relapse of major depressive disorder in the continuation phase of treatment. Psychosomatics 2004;45:419-425

85. Spina E, Scordo MG, D'Arrigo C. Metabolic drug interactions with new psychotropic agents. Fundam Clin Pharmacol 2003; 17:517-538

86. Unützer J, Katon W, Callahan CM, et al. Collaborative care management of late-life depression in the primary care setting: a randomized controlled trial. JAMA 2002;288:2836-2845

87. Rush AJ, Trivedi M, Carmody TJ, et al. One-year clinical outcomes of depressed public sector outpatients: a benchmark for subsequent studies. Biol Psychiatry 2004; $56: 46-53$

88. Trivedi MH, Rush AJ, Wisniewski SR, et al. Evaluation of outcomes with citalopram for depression using measurement-based care in STAR*D: implications for clinical practice. Am J Psychiatry 2006;163:28-40

89. Maines TY, Lavie CJ, Milani RV, et al. Effects of cardiac rehabilitation and exercise programs on exercise capacity, coronary risk factors, behavior, and quality of life in patients with coronary artery disease. South Med J 1997;90:43-49

90. Gaede P, Beck M, Vedel P, et al. Limited impact of lifestyle education in patients with type 2 diabetes mellitus and microalbuminuria: results from a randomized intervention study. Diabet Med 2001;18: 104-108

91. Keers JC, Bouma J, Links TP, et al. Oneyear follow-up effects of diabetes rehabilitation for patients with prolonged selfmanagement difficulties. Patient Educ Couns 2006;60:16-23

92. Linden W, Stossel C, Maurice J. Psychosocial interventions for patients with coronary artery disease: a meta-analysis. Arch Intern Med 1996;156:745-752

For the CME Posttest for this Academic Highuights, see pages 1656-1658. 